\title{
Impact of sound levels on physiological and consciousness state of cardiovascular patients
}

\author{
Ignacio Morales-Cané RN, MSc, PhD ${ }^{1,2,3}$ ～～Juan Antonio Moral-Arroyo RN, MSc ${ }^{1,2,3}$ \\ Fabio Debbia RN, MSc $^{1}$ ｜ Ipek Guler Mstat ${ }^{1}$ ｜ Francisca Llamas-Recio RN ${ }^{1,2,3}$ | \\ José Manuel Jiménez-Pastor $\mathrm{BIO}^{1,2,3}$ ｜ Juan de la Cruz López-Carrasco $\mathrm{RN}^{1,2,3}$ ( ) \\ Darío Acuña-Castroviejo MD, $\mathrm{PhD}^{4}$ । \\ María Aurora Rodríguez-Borrego RN, MSc, $\mathrm{PhD}^{1,2,3}$ | \\ Pablo Jesús López-Soto RN, MSc, PhD ${ }^{1,2,3}$
}

\author{
${ }^{1}$ Department of Nursing, Instituto Maimónides \\ de Investigación Biomédica de Córdoba \\ (IMIBIC), Córdoba, Spain \\ ${ }^{2}$ Department of Nursing, Pharmacology and \\ Physiotherapy, Universidad de Córdoba, \\ Córdoba, Spain \\ ${ }^{3}$ Department of Nursing, Hospital \\ Universitario Reina Sofía de Córdoba, \\ Córdoba, Spain \\ ${ }^{4}$ Department of Physiology, Faculty of \\ Medicine, Centro de Investigación Biomédica, \\ Parque Tecnológico de Ciencias de la Salud, \\ Universidad de Granada, Granada, Spain

\section{Correspondence} \\ Pablo Jesús López-Soto, Department of \\ Nursing, Instituto Maimónides de \\ Investigación Biomédica de Córdoba (IMIBIC) \\ Av. Menéndez Pidal s/n, Córdoba, Spain. \\ Email: pablo.lopez@imibic.org

\section{Funding information} \\ This research received specific grants from the \\ Regional Ministry of Health and Families, \\ Government of Andalusia. Reference: \\ PIGE-0462-2019. Principal investigator: \\ Morales-Cané I/Reference: PI-0360-2017. \\ Principal investigator: López-Soto PJ.
}

\begin{abstract}
Background: Patients treated in intensive care units (ICUs) experience lifethreatening medical conditions but some external factors in ICUs do not help or even adversely affect and complicate their evolution. Among others, such factors include noise pollution due to alarms and medical clinical equipment, as well as the activities of the health care personnel themselves.

Aim: This study aimed to evaluate the influence of elevated sound levels on physiological variables and the consciousness state of patients treated in a cardiovascular area in an ICU.

Design: A longitudinal study with several observations was carried out during 1 month in the cardiovascular area of an ICU of a third-level hospital in southern Spain.

Methods: Sound levels were monitored in different work shifts and patients' physiological data and consciousness status were recorded. Generalized additive mixed models (GAMMs) were developed to detect the variability of the sound levels together with the vital parameters of the patients in the ICU.

Results: Thirty-eight patients were included. The mean sound level was 54.09 dBA. The GAMM sound levels analysis showed a significant increase in sound levels from 4:30 p.m. to 8:00 p.m. (1.83 dBA; $P<.001$ ) and 8:00 p.m. to 11:30 p.m. (3.06 dBA; $P<.001)$. An increase in heart rate $(3.66 \mathrm{bpm} ; P<.001)$, respiratory rate $(2.62 \mathrm{rpm}$; $P<.001)$ and the Glasgow Coma Scale $(0.50$ units; $P=.002)$ was detected during the 4:30 p.m. $-8: 30$ p.m. period.
\end{abstract}


Conclusions: Elevated sound levels in cardiovascular ICUs seem to influence positively the physiological and consciousness status of patients. Given the importance of the findings for patient safety, future intervention studies are recommended.

Relevance to Clinical Practice: The finding of this study could translate into structural changes in ICU facilities, as well as the development of clinical practice guidelines that influence the behaviour of health care professionals.

\section{KEYWORDS}

critically ill patients, environment, intensive care unit, noise, safety culture

\section{$1 \mid$ INTRODUCTION}

\section{1 | Background}

Noise is recognized by the World Health Organization (WHO) in 2018 , to be "one of the most important environmental risks to health" and "a growing concern among policy-makers and the public alike."1 Noise or unwanted sound, not merely elevated sound levels, is that auditory stimulus or stimuli bearing no informational relationship to the presence or completion of the immediate task. ${ }^{2}$ Logarithmic decibel $(\mathrm{dB})$ units are used to measure the intensity of sound. The A-weighted filter is commonly used. In this standardized filter, sensitivity varies in the same way as the human ear and modifies the frequency response to follow a similar loudness curve of 40 phons. $^{3}$

Historically, intensive care units (ICUs) are known to experience elevated sound levels above the established limits ${ }^{4,5}$ which the WHO sets at $30 \mathrm{dBA}$ for nighttime. ${ }^{6}$ Several studies have reported mean noise levels in ICUs to range between 50 and $65 \mathrm{dBA}^{7,8}$ and in some cases between 70 and $85 \mathrm{dBA}$, or even over $90 \mathrm{dBA}$, $^{9,10}$

ICU environments are the source of various types of elevated sounds (professionals and families' conversations, frequent diagnostic and therapeutic procedures, monitor alarms, mechanical ventilation, phones, doorbells, door closures, etc.), and the association between elevated sound and sleep disturbance and its effect on patients' physiological and psychological well-being has been widely investigated. ${ }^{5,7-9}$ Observational studies have shown that sleep in ICUs is often fragmented and of a markedly abnormal quality ${ }^{11}$ and has important consequences on circadian rhythms, ${ }^{12}$ or how nursing interventions to abate ambient stressors enhance patients' sleep. ${ }^{13}$ Indeed, the Society of Critical Care Medicine in 2018 published a document entitled "Clinical Practice Guidelines for the Prevention and Management of Pain, Agitation/Sedation, Delirium, Immobility, and Sleep disruption in Adult Patients in the ICU" which recommends using noise and light reduction strategies to improve sleep in critically ill adults. ${ }^{14}$

In 2003, the Spanish legislation introduced a law on the assessment and management of environmental noise (Law 37/2003 de November 17th, for the noise). This law transposed and incorporated the European recommendation contained in Directive 2002/49/CE, which defines environmental noise as "unwanted or harmful outdoor

\section{WHAT IS KNOWN ABOUT THIS TOPIC}

- Heart rate and blood pressure in post-cardiac surgery patients are affected by sound levels generated by ICU medical devices

- Previous studies assumed that all relations between the sound levels and physical effects are linear

\section{WHAT THIS PAPER ADDS}

- Fluctuations in sound levels and alterations in physiological variables (heart rate and respiratory rate) and the Glasgow Coma Scale coincide at the same time

- Our study introduces non-linear profiles of noise together with vital parameters; flexible statistical methods are, therefore, required to capture the changes over time appropriately.

sound created by human activities, including noise emitted by means of transport, road traffic, rail traffic, air traffic, and from sites of industrial activity [...] concerning integrated pollution prevention and control." ${ }^{\text {"15 }}$ Furthermore, the technical guide of the Spanish National Institute of Occupational Health and Safety establishes explicit recommendations for elevated sound level limits in several environments (Royal Decree 286/2006, Spanish Official Gazette no. 22). ${ }^{16}$ Consistently with WHO indications, for example, hospitals are recommended not to exceed values between 25 and $35 \mathrm{dBA} .{ }^{1}$ However, none of these recommendations are specific to ICUs.

\subsection{Aims and objectives of the study}

Cardiovascular ICUs, the scope of the research study, are responsible for providing post-operative care for patients receiving cardiac surgery. These patients used to experience physical and psychological threats from surgery. A study by Hsu et al reported a positive association between sound levels generated by ICU medical devices with 
elevated heart rate and blood pressure in post-cardiac surgery patients. ${ }^{17}$ To the best of our knowledge, previous studies assume that all relations between the sound levels and physical effects are linear. However, to detect the non-linear profiles of the noise together with the vital parameters, flexible statistical methods are needed to capture the changes over time appropriately. The generalized additive mixed models (GAMM) are commonly used to capture the non-linear time effects on the response variable. ${ }^{18}$

Therefore, to evaluate the sound levels of a cardiovascular ICU in a third-level university hospital in southern Spain, and the possible correlations of such a situation with patients' physiological and consciousness state, we have performed independent GAMM.

\section{2 | METHODS}

This descriptive correlational study longitudinally analysed patients treated in the month of June 2018 to the cardiovascular ICU of a third-level hospital in southern Spain. A STROBE checklist was used to guide this paper.

\subsection{Setting and participants}

In this study, participants were required to be aged over 18 years and be treated in the cardiovascular ICU for at least 24 hours. Pregnant women, patients admitted to restricted access module (immate of the penitentiary system) or with a high probability of death at 24-48 hours were excluded (determined by the APACHE II ${ }^{17}$ scale at baseline; patients with scores above 35 were excluded). Participants were included by consecutive sampling on random shifts and days of the month.

In the study by $\mathrm{Hsu}$ et $\mathrm{al}^{18}$ sound levels had an impact on heart rate by $1.40+0.71$ beats per minute. Therefore, a random sample of at least 23 individuals was sufficient to estimate, with a confidence of $95 \%$ and an accuracy of $+/-0.2$ units, taking into account a standard deviation of around 0.71 units. The necessary replacement percentage was expected to be $10 \%$.

The time of the work shifts in the ICU under study were morning (8:00 a.m.-3:00 p.m.), afternoon (3:00 p.m.-10:00 p.m.) and night (10:00 p.m.-8:00 a.m.). In each shift, the number of nurses is 4 and 2 nursing assistants. In addition, there are usually two doctors on the morning shift and one on the afternoon and evening shifts.

The studied cardiovascular ICU has a total of 8 beds and is specialized in the diagnosis, management and monitoring of patients with cardiac and cardiovascular pathology. The unit is structured in the form of a rectangle with open beds on the narrower sides (two on each side) and 5 semi-closed cubicles on the wider sides ( 4 were patient beds and one a small office for clinicians). An open nursing station is located on the other wider side. Figure 1 shows a diagram of half the unit.

According to hospital regulations, two visits of a maximum length of 35-40 minutes are allowed per day at 1:00 p.m. and 8:00 p.m. Also, during the afternoon, this unit has a higher number of admissions due to scheduled prosthetic valve surgeries.

\section{2 | Variables and instruments}

Sound levels were monitored in logarithmic decibels (dB) units with an A-weighted filter during the different work shifts and the following data were on patients' physiological state were collected using a physiologic monitor (Philips, IntelliVue MP5, Amsterdam, Netherlands): (a) heart rate; (b) respiratory rate; (c) oxygen saturation and (d) blood pressure. The level of consciousness was established by the Glasgow Coma Scale and sedation according to the Ramsay Sedation Scale. The administration of vasoactive drugs (ie, adrenaline or norepinephrine) and sedatives and relaxants (ie, midazolam, propofol, fentanyl or morphic chloride) was recorded. Data relating to the use or not of mechanical ventilation, as well as other clinical and sociodemographic variables (length of stay, clinical diagnoses, age and gender) were also collected.

\section{3 | Procedure}

The clinical variables were obtained from the UCIMNOVA 2.0 application. This application is being used in the study ICU (already registered as a patent) for the follow-up of patients and including clinical variables related to medical and nursing interventions. Sound levels were measured using a Class II sound level meter (Sauter SW 2000, Sauter $\mathrm{GmbH}$, Balingen, Germany; meeting the international standard IEC61672-1:2014-07), calibrated by the manufacturer prior to the collection period (Model 961-281) (Kern). Microsoft Excel, SAUTER AFI-1.0 was used to transmit the sound level meter data to a computer. It was used to measure sound levels in $\mathrm{dBA}$, being the measuring range between 25 and $136 \mathrm{dBA}$, frequency range 0.02 to $12.5 \mathrm{kHz}$ and sensitivity $40 \mathrm{mV} / \mathrm{Pa}$. The sound level meter was placed right in the middle of the unit, approximately $5.06 \pm 0.56$ [range: 6.03-4.01] $\mathrm{m}$ from the patients' heads. The microphone was $1.20 \mathrm{~m}$ above the ground and $2.30 \mathrm{~m}$ below the ceiling. The flooring and wall materials are continuous homogeneous vinyl. Ceiling materials are continuous sheets of cardboard/gypsum plasterboard.

Sound values were recorded every 2 seconds during each work shift. A qualified researcher documented the physiological variables every 15 minutes (recordings were also programmed in the physiological monitors), and the Ramsay and Glasgow Coma Scale, as well as doses of vasoactive, sedative and relaxant drugs, which were recorded every 2 hours. The patients' length of stay, clinical diagnoses, age and gender, and use or not of mechanical ventilation were collected at the beginning and end of each shift. The total number of shifts included in the study were (a) 4 morning shifts, 5 afternoon shifts and 1 night shift on weekdays and (b) 1 night shift on weekends.

\subsection{Data analysis}

The patients' characteristics were determined using descriptive statistics such as measures of frequency, central tendency and dispersion depending on the type of variable (quantitative or qualitative). 


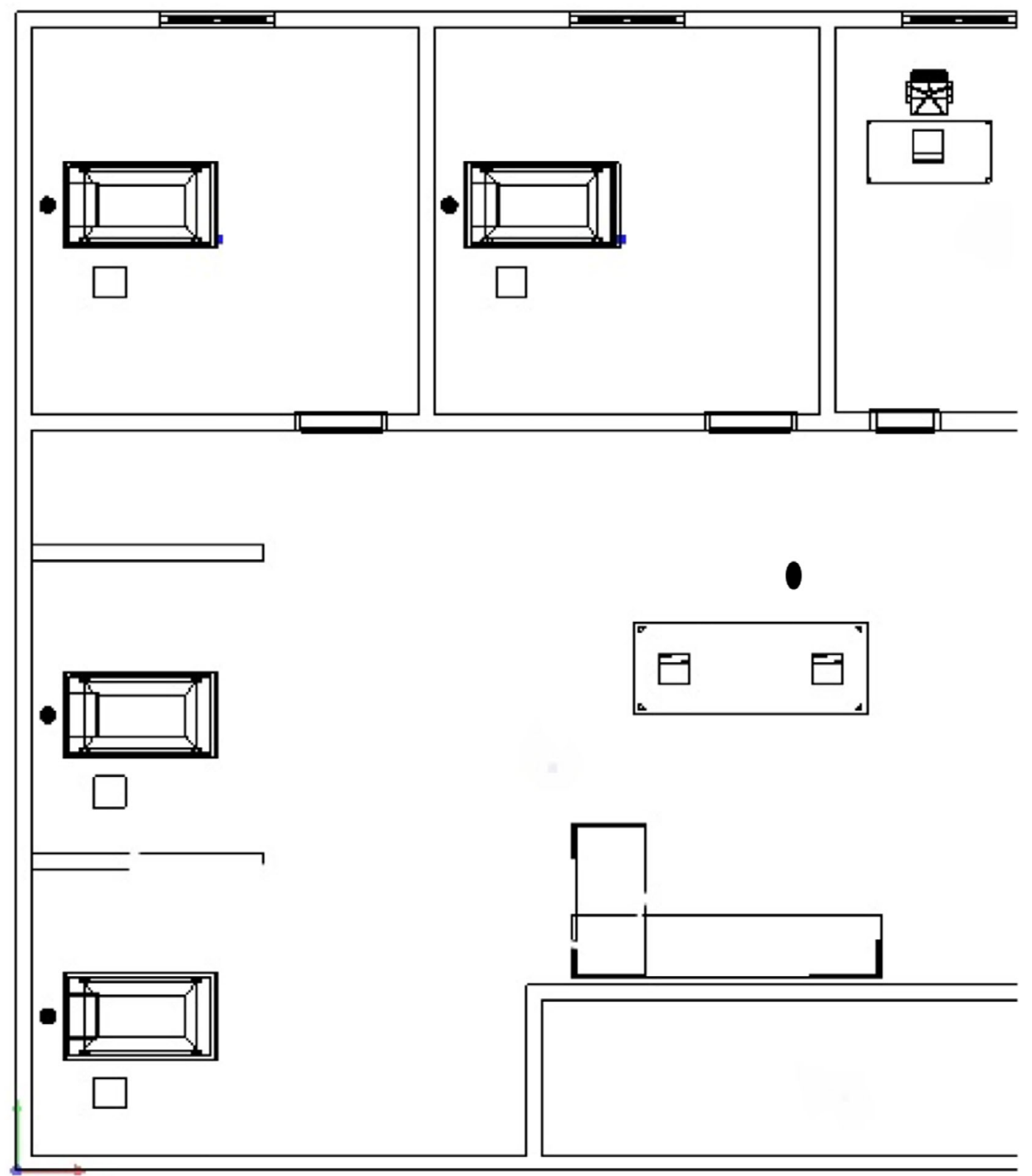

FIGURE 1 Diagram of half of the eight bedded space (not to scale)

Normality was checked by the Shapiro-Wilk test and homogeneity of variance with the Levene test. Differences in sound levels according to shift work were examined by comparing mean values of decibel across the three-shift work categories using analysis of variance (ANOVA).

To model the non-linear trends of sound levels and the nonlinear vital parameters of the patients in the ICU, GAMMs were developed.

The reason for the chosen statistical methods, GAMMs, is twofold: (a) the variation of repeated measurements within and between subjects has to be taken into account as the sound and the vital parameters are measured repeatedly over time for the same patient and (b) the non-linear effect of time on the sound levels and vital parameters can be captured using smoothing splines.
The intercept and slope effects were considered as random effects in all the GAMMs and were assumed to be normally distributed. GAMMs are commonly used to study both the variation of repeated measurements within and between subjects with random effects as well as the non-linear effects of covariates on the response variable with a smooth function of the covariate. ${ }^{19}$ These flexible smoothing techniques help to capture small increases and decreases in the outcome variable during the follow-up period. As indicated in Figure 2 representing the overall curves for sound and the vital parameters of patients, the trajectories present a non-linear nature over time. Thus, we used penalized cubic spline smoothing for the effect of time indicated with function $s()$ in GAMMs.

For the change in sound levels, we only considered the smooth time effect on the response variable. For the respiratory rate, Glasgow 
Coma Scale and heart rate, the following covariates were considered: age, gender, length of stay, mechanical ventilation and pharmacology. We have used the time effect both for fixed and random effects, the smooth effect of time has been considered as fixed effects. The shifts of ICU control (time intervals) were considered as another covariate in the model, to observe the change in different control times. The effect of mechanical ventilation was studied by a smooth interaction effect with the time variable to obtain different curves for patients who had mechanical ventilation and those who did not. In all the GAMMs, the intercept and slope effects were considered as random effects and assumed to be normally distributed. We considered all the variables presented in Table 1 as covariates in the model and performed a variable selection depending on the Akaike Information Criterion value of the model.

All analyses were performed using the free software $\mathrm{R}$ (version 3.5.0). The GAMMs were fitted using the $m g c v$ package.

\section{5 | Ethical considerations}

The study was conducted according to the guidelines of the Declaration of Helsinki and approved by the Ethics Committee of the author's institution (Act $n^{\circ} 277$; ref. 3878). All patients were older than 18 years and gave their consent to participate voluntarily in the study.

Prior to inclusion in the study, patients were provided with an information sheet, and informed consent was obtained from all participants included in the study. If patients were unable to give their consent due to their clinical condition, consent was requested from families.

\section{3 | RESULTS}

\subsection{Demographic and clinical variables}

In June 2018 there were 59 hospital admissions in the aforementioned ICU. The study participants ( $N=38$ ) represent $64.4 \%$ of the patients admitted to the ICU. Clinical data were recorded prospectively. The majority of the participants were male $(63.1 \% ; n=24)$ with median age of 67 [45.6-72.1] years. Baseline demographic and clinical variables are shown in Table 1.

\subsection{Sound levels and GAMM models}

A total of 149390 records were captured by the sound level meter. The average sound value (Leq) captured by the sound level meter was 54.09 (SD = 5.03) dBA with a maximum value (Lmax) of $104.2 \mathrm{dBA}$ and a minimum value ( $\mathrm{Lmin}$ ) of $45.9 \mathrm{dBA}$. In relation to the average sound values (Leq) recorded in each work shift, the afternoon work shifts (55.35 dBA, SD $=5.22$ ) were significantly louder than the morning shifts $(53.95 \mathrm{dBA}, \mathrm{SD}=4.90)$ and night shifts (52.14 dBA, $\mathrm{SD}=4.18 ; F=63.87 ; P<.001)$.
FIGURE 2 Overall curves for sound and the vital parameters of patients

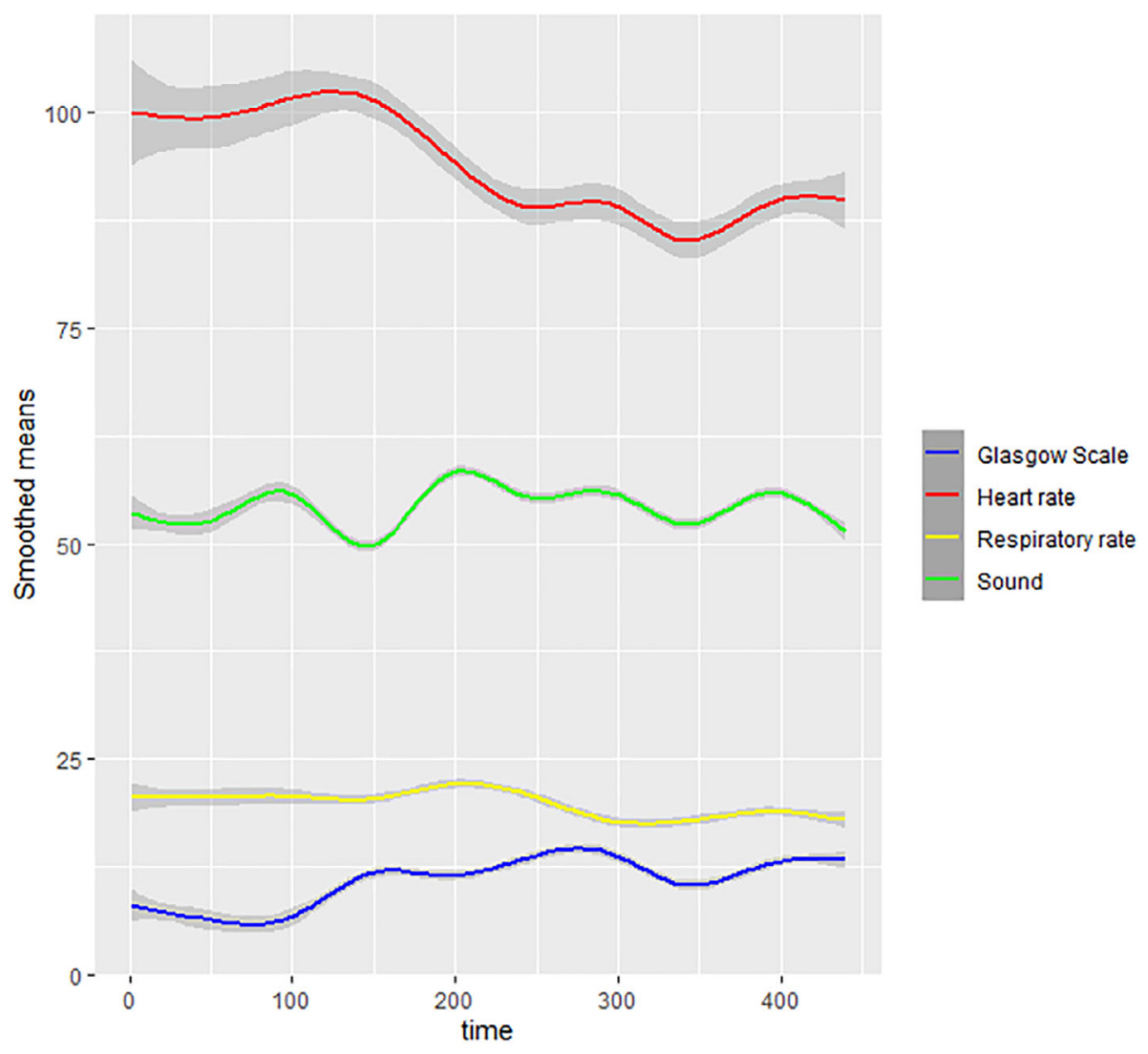


TAB LE 1 Baseline demographic, medication and clinical variables for the ICU sample

\begin{tabular}{|c|c|c|}
\hline \multicolumn{2}{|l|}{ Variables (units) } & Total $(\mathbf{N}=38)^{\mathrm{a}}$ \\
\hline \multicolumn{2}{|l|}{ Age (years) } & $59.7(20.3)$ \\
\hline \multicolumn{3}{|l|}{ Gender } \\
\hline \multicolumn{2}{|l|}{ Male } & $24(63.2 \%)$ \\
\hline \multicolumn{2}{|l|}{ Female } & $14(36.8 \%)$ \\
\hline \multicolumn{2}{|l|}{ Elective admission } & 30 (78.9\%) \\
\hline \multicolumn{2}{|l|}{ Emergency admission } & $8(21.1 \%)$ \\
\hline \multicolumn{3}{|l|}{ Clinical diagnoses } \\
\hline \multicolumn{2}{|l|}{ Cardiogenic shock } & $1(2.6 \%)$ \\
\hline \multicolumn{2}{|l|}{ Cardiac heart failure } & $1(2.6 \%)$ \\
\hline \multicolumn{2}{|l|}{ Extracorporeal intervention } & $14(36.8 \%)$ \\
\hline \multicolumn{2}{|l|}{ Implantable cardioverter defibrillator } & $1(2.6 \%)$ \\
\hline \multicolumn{2}{|l|}{ Pre-heart transplant } & $1(2.6 \%)$ \\
\hline \multicolumn{2}{|l|}{ Subarachnoid haemorrhage } & $2(5.2 \%)$ \\
\hline \multicolumn{2}{|l|}{ Sepsis } & $1(2.6 \%)$ \\
\hline \multicolumn{2}{|c|}{ ST segment elevation myocardial infarction } & $4(10.5 \%)$ \\
\hline \multicolumn{2}{|l|}{ Transcatheter aortic valve implantation } & $13(34.2 \%)$ \\
\hline \multicolumn{2}{|l|}{ Mechanical ventilation (presence) } & 15 (39.5\%) \\
\hline \multicolumn{2}{|l|}{ Heart rate (beat per minute) } & $91.4(17.7)$ \\
\hline \multicolumn{2}{|l|}{ Respiratory rate (breath per minute) } & $18.1(4.21)$ \\
\hline \multicolumn{2}{|l|}{ Oxygen saturation (\%) } & $94.4(16.3)$ \\
\hline \multicolumn{2}{|l|}{ Systolic blood pressure $(\mathrm{mmHg})$} & $112(22.9)$ \\
\hline \multicolumn{2}{|l|}{ Diastolic blood pressure (mmHg) } & $59.9(12.1)$ \\
\hline \multicolumn{2}{|l|}{ Mean arterial blood pressure $(\mathrm{mmHg})$} & $85.9(16.1)$ \\
\hline \multicolumn{2}{|l|}{ Glasgow coma scale (points) } & $10.7(5.42)$ \\
\hline \multicolumn{2}{|l|}{ Ramsay sedation scale (points) } & $3.37(1.76)$ \\
\hline \multicolumn{2}{|l|}{ Length of stay (days) } & $2.76(5.46)$ \\
\hline Medication (units) & $\mathrm{n}$ & Mean $(\mathrm{SD})^{\mathrm{b}}$ \\
\hline Epinephrine (mcg/kg/min) & 15 & $0.20(0.23)$ \\
\hline Norepinephrine (mcg/kg/min) & 28 & $0.29(0.31)$ \\
\hline Midazolam (mL) & 2 & $1.65(1.23)$ \\
\hline Propofol (mL) & 8 & $4.37(4.46)$ \\
\hline Fentanyl (mL) & 4 & $0.94(0.92)$ \\
\hline
\end{tabular}

${ }^{a}$ Categorical variables were expressed in absolute frequency (percentage) and continuous variables in mean (standard deviation).

bIn medication, mean and standard deviation (SD) values were established for those patients who received treatment (n). Note: Morphic chloride was used in one patient.

In the GAMM model for sound levels, the fixed effect of time intervals showed significant effect and increasing sound levels detected in the 4:30 p.m.-8:00 p.m. (coef.: 1.83; $P<.001$ ) and 8:00 p.m. to $11: 30$ p.m. (coef.: $3.06 ; P<.001$ ) time periods with respect to the 6:00 a.m.-9:30 a.m. time period. In contrast, a significant decrease in sound levels was detected from 9:30 a.m. to 1:00 p.m. (coef.: -1.11 ; $P=.01$ ) and 3:00 a.m. to 6:00 a.m. (coef.: $-2.84 ; P<.001$ ) (Table 2A).

A significant increase in the heart rate model was also observed in the same period as in the sound levels model: 4:30 p.m. to 8:00 p. m. and $8: 00$ p.m. to $11: 30$ p.m. $(P<.001)$; however, the longer the stay, the lower the heart rate levels (coef.: $-0.75 ; P=.01$ ). Additionally, the medications that the patients were being administered did not significantly affect the heart rate (Table $2 \mathrm{~B}$ ).

Considering the 6:00 a.m. to 9:30 a.m. time period as a reference, higher respiratory rate values (Table $2 \mathrm{C}$ ) were found in all time periods, $(P<.001)$ except for 3:00 a.m. to 6 a.m. The largest increase occurred in the 1:00 p.m. to 4:30 p.m., 4:30 p.m. to 8:00 p.m. and 8:00 p.m. to $11: 30$ p.m. time periods, while a significant decrease in age and fentanyl with respect to respiratory frequency was found $(P=.03$, .01 respectively). Moreover, when midazolam or propofol was administered, an increase in respiratory rate was detected; indeed, there was a statistically significant difference but this was not clinically significant. Regarding the Glasgow Coma Scale model, the 4:30 p.m. to 8:00 p.m. time period showed significantly high values coinciding with the changes in the sound levels model $(P=.002$, Table 2D). In the same line and paradoxically, higher Glasgow Coma Scale values were associated with a longer ICU stay. As expected, the Glasgow Coma Scale values were significantly lower when midazolam or propofol was used $(P<.001)$.

The centred smooth effect of time for each response variable (sound levels, heart rate and respiratory rate) is presented in Figure 3. As can be seen in Figure 3A, the sound levels were lower at the beginning, decreased over time (bathyphase: 125 hours) and then increased between 200 and 300 hours, after which the values stabilized. Indeed, a statistically significant curve was observed in the heart rate of patients with mechanical ventilation (coef. $=7.07 ; P=.0253$ ) (Figure 3B), although the heart rate of patients with no mechanical ventilation seemed to be more stabilized (coef. $=3.67 ; P=.4707$ ). As shown in Figure $3 C$, for patients with or without mechanical ventilation, the respiratory rate curves were significant and similar and slightly increased at the end of the measurement period in the case of non-mechanically ventilated patients. Thus, at the end of the observational study, high noise levels coincided with high respiratory rate levels in those non-mechanically ventilated patients.

\section{4 | DISCUSSION}

In 1859, Florence Nightingale, a pioneering figure in the nursing profession, wrote that "unnecessary noise ... is the most cruel abuse of care which can be inflicted either on sick or well." ${ }^{20}$ Indeed, hospital noise is considered one of the main factors that cause disruption in patients' length-of-stay, ${ }^{21}$ but is the most stressful factor for patients particularly in ICUs. ${ }^{10}$

The average sound level (54.09 dBA; SD 5.03) in the ICU studied here exceeds the recommended levels proposed by the WHO. ${ }^{1}$ Similar results have been found in other studies performed in ICUs with sound levels exceeding $50 \mathrm{dBA} \cdot{ }^{10,22-24}$ We found that the afternoon-evening shift was the loudest, specifically the time period between 4:30 p.m. and 11:30 p.m. Higher sound values can be explained by family or staff conversations during visits as well as the greater number of admissions in this area of the ICU from scheduled valve prosthesis surgeries, which usually arrive at the unit in the afternoon. ${ }^{10,25,26}$ 
TAB LE 2 Fixed effects models in the study area: (A) model of noise; (B) model of heart rate; (C) model of respiratory rate and (D) model of Glasgow Coma Scale

\begin{tabular}{|c|c|c|}
\hline $\begin{array}{l}\text { A } \\
\text { Variables }\end{array}$ & $\begin{array}{l}\text { Model of noise } \\
\text { fixed effects } \\
\text { Coef. (SD) }\end{array}$ & $P$ \\
\hline \multicolumn{3}{|l|}{ Reference: 6:00 a.m. to 09:30 a.m. } \\
\hline 09:30 a.m. to 01:00 p.m. & $-1.117(0.452)$ & .0137 \\
\hline 1:00 p.m. to $4: 30$ p.m. & $0.553(0.475)$ & .244 \\
\hline 4:30 p.m. to $8: 00$ p.m. & $1.838(0.530)$ & .0005 \\
\hline 8:00 p.m. to $11: 30$ p.m. & $3.063(0.554)$ & $<.001$ \\
\hline 11:30 p.m. to 3:00 a.m. & $-0.292(0.571)$ & .6090 \\
\hline 3:00 a.m. to $6: 00$ a.m. & $-2844(0.550)$ & $<.001$ \\
\hline $\begin{array}{l}\text { B } \\
\text { Age } \\
\text { Female }\end{array}$ & $\begin{array}{l}\text { Model of heart } \\
\text { rate Fixed effect } \\
-0.0711(0.224) \\
-6.227(9.282)\end{array}$ & $\begin{array}{l}.753 \\
.5068\end{array}$ \\
\hline \multicolumn{3}{|l|}{ Reference 6:00 a.m.-09:30 a.m. } \\
\hline 09:30 a.m. to 01:00 p.m. & $1.352(0.827)$ & .1022 \\
\hline 1:00 p.m. to $4: 30$ p.m. & $6.456(0.871)$ & $<.001$ \\
\hline 4:30 p.m. to $8: 00$ p.m. & $3.669(0.892)$ & $<.001$ \\
\hline 8:00 p.m. to $11: 30$ p.m. & $4.361(0.903)$ & $<.001$ \\
\hline 11:30 p.m. to 3:00 a.m. & $-0.638(0.965)$ & .5085 \\
\hline 3:00 a.m. to 6:00 a.m. & $0.654(0.888)$ & .4614 \\
\hline Adrenalin & $-3.566(2.209)$ & .1068 \\
\hline Length of stay & $-0.756(0.306)$ & .0135 \\
\hline $\begin{array}{l}\text { Combination Midazolam } \\
\text { and Propofol }\end{array}$ & $-0.738(5.299)$ & .8892 \\
\hline Midazolam or Propofol & $-0.487(1.366)$ & .7217 \\
\hline Fentanyl & $0.383(3.996)$ & .9236 \\
\hline \multirow[t]{2}{*}{ Morphic chloride } & $24.754(26.265)$ & .3526 \\
\hline & DF & $P$ \\
\hline $\mathrm{s}($ time $){ }^{*}$ nO mechanized ventilation & 3.677 & .4707 \\
\hline$s(\text { time })^{*}$ mechanized ventilation & 7.075 & .0253 \\
\hline $\begin{array}{l}\text { C } \\
\text { Age } \\
\text { Female }\end{array}$ & $\begin{array}{l}\text { Model of respiratory } \\
\text { rate fixed effects } \\
-0.090(0.0415) \\
-0.199(1.772)\end{array}$ & $\begin{array}{l}.0357 \\
.4191\end{array}$ \\
\hline \multicolumn{3}{|l|}{ Ref (6:00 a.m. to 09:30 a.m.) } \\
\hline 09:30 a.m. to 01:00 p.m. & $0.860(0.318)$ & .0069 \\
\hline 1:00 p.m. to $4: 30$ p.m. & $2.395(0.334)$ & $<.001$ \\
\hline 4:30 p.m. to $8: 00$ p.m. & $2.620(0.349)$ & $<.001$ \\
\hline 8:00 p.m. to $11: 30$ p.m. & $3.244(0.349)$ & $<.001$ \\
\hline 11:30 p.m. to 3:00 a.m. & $1.165(0.384)$ & .0025 \\
\hline 3:00 a.m. to $6: 00$ a.m. & $0.176(0.356)$ & .6215 \\
\hline Length of stay & $-0.069(0.085)$ & .4190 \\
\hline $\begin{array}{l}\text { Combination Midazolam and } \\
\text { Propofol }\end{array}$ & $2.476(2.019)$ & .2203 \\
\hline Midazolam or Propofol & $0.966(0.511)$ & .0587 \\
\hline Fentanyl & $-3.681(1.524)$ & .0159 \\
\hline
\end{tabular}

(Continues)
TABLE 2 (Continued)

\begin{tabular}{|c|c|c|}
\hline $\begin{array}{l}\text { C } \\
\text { Age } \\
\text { Female }\end{array}$ & $\begin{array}{l}\text { Model of respiratory } \\
\text { rate fixed effects } \\
-0.090(0.0415) \\
-0.199(1.772)\end{array}$ & $\begin{array}{l}.0357 \\
.4191\end{array}$ \\
\hline \multicolumn{3}{|l|}{ Ref (6:00 a.m. to $09: 30$ a.m.) } \\
\hline \multirow[t]{2}{*}{ Morphic chloride } & $-2.120(5.072)$ & .6785 \\
\hline & $D F$ & $p$ \\
\hline $\begin{array}{l}\mathrm{s}(\text { time }) * \text { no mechanized } \\
\text { ventilation }\end{array}$ & 6.036 & $<.001$ \\
\hline $\mathrm{s}($ time $){ }^{*}$ mechanized ventilation & 5.610 & $<.001$ \\
\hline $\begin{array}{l}\text { D } \\
\text { Age } \\
\text { Female }\end{array}$ & $\begin{array}{l}\text { Model of } \\
\text { Glasgow } \\
\text { fixed effects } \\
0.188(0.117) \\
0.867(4.893)\end{array}$ & $\begin{array}{l}.1188 \\
.8603\end{array}$ \\
\hline \multicolumn{3}{|l|}{$\operatorname{Ref}(6: 00$ a.m. to $09: 30$ a.m.) } \\
\hline 09:30 a.m. to 01:00 p.m. & $0.104(0.155)$ & .5012 \\
\hline 1:00 p.m. to $4: 30$ p.m. & $-0.0642(0.161)$ & .6910 \\
\hline 4:30 p.m. to $8: 00$ p.m. & $0.508(0.169)$ & .0028 \\
\hline 8:00 p.m. to $11: 30$ p.m. & $0.180(0.181)$ & .3186 \\
\hline 11:30 p.m. to $3: 00$ a.m. & $-0.063(0.185)$ & .7311 \\
\hline 3:00 a.m. to $6: 00$ a.m. & $-0.284(0.160)$ & .7299 \\
\hline $\begin{array}{l}\text { Combination Midazolan and } \\
\text { Propofol }\end{array}$ & $-0.567(0.911)$ & .5335 \\
\hline Midazolan or Propofol & $-3.594(0.233)$ & $<.001$ \\
\hline Days of stay & $0.302(0.0657)$ & $<.001$ \\
\hline Fentanyl & $0.010(0.343)$ & .9765 \\
\hline \multirow[t]{2}{*}{ Morphic cloride } & $4.007(14.535)$ & .6216 \\
\hline & DF & $p$ \\
\hline s(time). & 8.655 & $<.001$ \\
\hline
\end{tabular}

Note: Coef. (SD), Coefficient (Standard deviation); DF, Degrees of freedom; s, smooth function with penalized cubic regression splines. The bolded values are represent $p<0.05$.

Figure 2 clearly shows the non-linear profiles of sound and vital parameters over time, thus an appropriate statistical technique was GAMMs which are commonly used in the literature for non-linear time effect on repeated measurements. Although this flexible smoothing technique does not establish cause-effect relationships and therefore limits the clinical importance, it does capture small increases and decreases independent variables during the study. We found a statistically significant increase in physiological variables (heart rate, respiratory rate and the Glasgow Coma Scale) at the same time that level of sound increased. Interestingly, during the period from 4:30 p.m.. to 8:30 p.m. increased sound levels were significantly associated with heart rate, respiratory and Glasgow Coma Scale models. While these results are of great relevance to patient safety as there appears to be an effect of sound levels on hospitalized patients in terms of heart rate, respiratory rate and Glasgow Coma Scale, future studies are required in which we can incorporate individual patient devices and register more environmental (light, humidity and temperature) and clinical (body temperature) variables. 

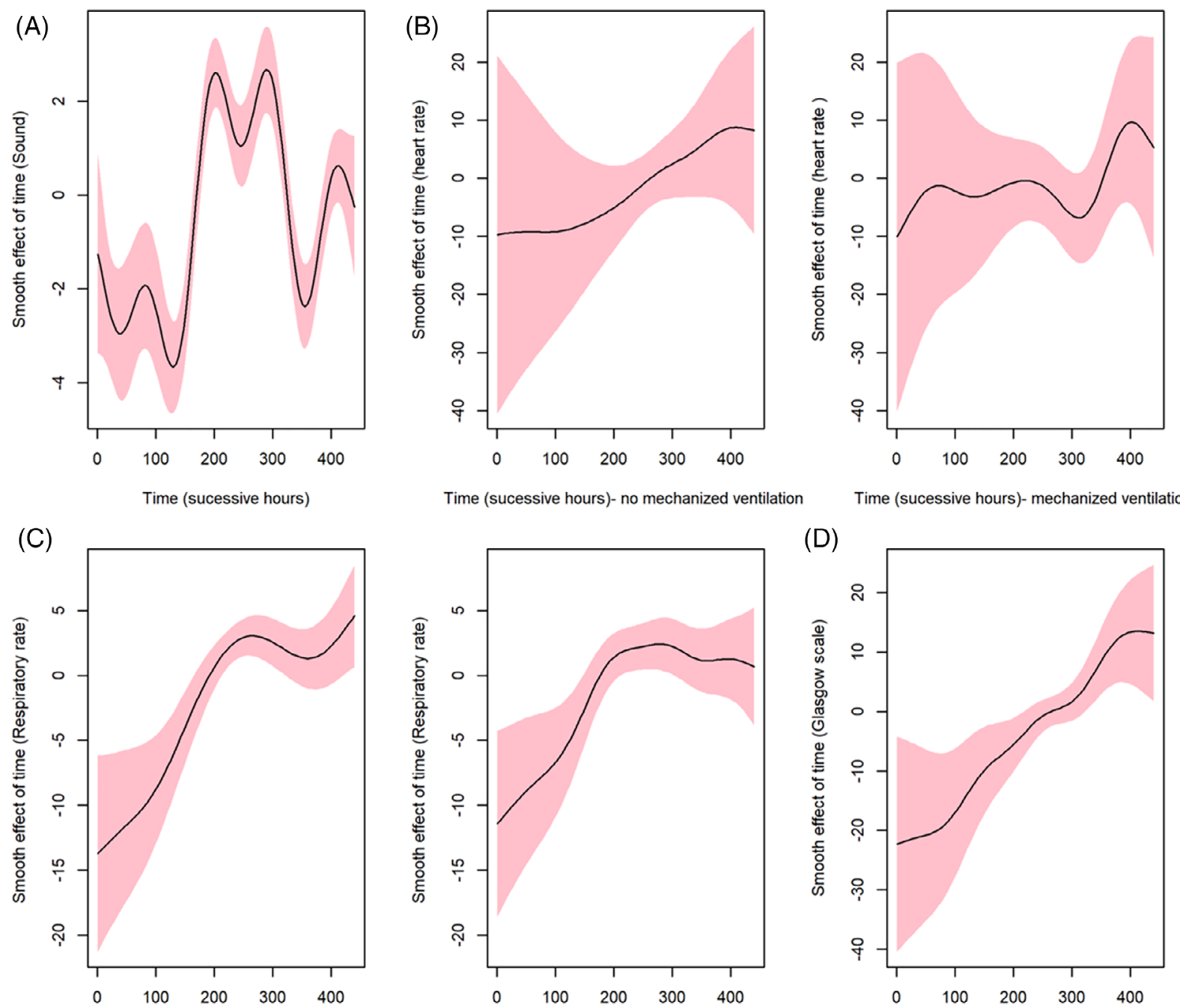

Time (sucessive hours)- no mechanized ventilation

Time (sucessive hours)- mechanized ventilation
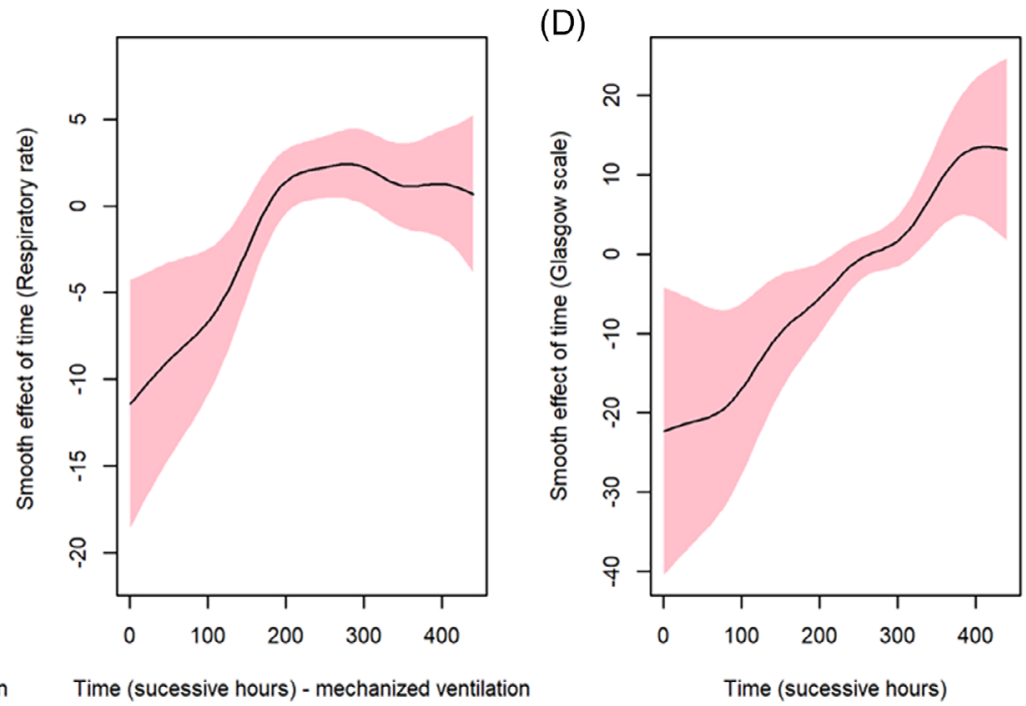

Time (sucessive hours)- no mechanized ventilation

Time (sucessive hours) - mechanized ventilation

FIGURE 3 Smooth effects of time graphs: A) noise; B) heart rate (right: mechanized ventilation; left: no mechanized ventilation); C) respiratory rate (right: mechanized ventilation; left: no mechanized ventilation) and D) Glasgow Coma Scale

Other studies ${ }^{10,27}$ have reported an increase in heart rate in noisy environments and suggested that such increases are triggered by vasoconstriction, highlighting that long-term noise leads to disruption of vascular and endothelial function. It has also been suggested that changes in heart rate may be due to the intensity and suddenness of the sound levels. ${ }^{28}$ Although we observed higher respiratory rates in periods with higher sound levels, differences were found depending on the type of ventilation (with a higher increase at the end of the analysis for non-mechanically ventilated patients). In the present study, most of the patients included were patients who had undergone cardiovascular surgery. In these patients, even slight variations in physiological variables (heart rate, respiratory rate and Glasgow scale) can alter the recovery of the acute process, leading to a longer stay in the ICU, increased tendency to delirium and a higher risk of ischemic heart disease. In this sense, high sound levels can trigger a series of stress hormones that affect tissue synthesis and metabolism, and consequently the physiological variables of the person admitted to the ICU. ${ }^{18,23}$ Reducing sound levels would help both to improve the physiological situation and overall well-being of patients and the level of satisfaction of the professionals who carry out their care tasks in the ICU. As shown in our findings, length of stay is associated with the heart rate and Glasgow coma Scale models. Therefore, the implementation of sound reduction programmes can lead to a reduction in the number of days patients spend in the ICU.

As expected, the administration of sedative drugs showed a negative association with the Glasgow Coma Scale. Specifically, the lowest Glasgow Coma Scale was found when either midazolam or propofol was administered. Interestingly, when sound levels were higher, the level of consciousness increased. Although elevated sound levels may be a trigger for greater patient alertness (higher Glasgow Coma Scale), another study in patients with traumatic brain injury showed that patients with Glasgow levels <8 were exposed to more monitor alarms than patients with a higher score. However, the authors did not establish a cause-effect relationship between alarm noise and the Glasgow Coma Scale. ${ }^{29}$ Therefore, to establish the existence of a cause-effect relationship, it would be necessary to perform individual 
measurements on each patient to determine whether alarms or other environmental factors alter the state of consciousness.

McAndrew et $\mathrm{al}^{30}$ and Alsulami et $\mathrm{al}^{31}$ reported that more prospective studies are needed to establish associations between the administration of sedatives and sound levels in patients admitted to the ICU, and if a correlation does exist, implement sound reduction strategies to reduce the dose of sedatives administered. The authors found that a quiet-time intervention reduced the respiratory rate and administration of sedatives in mechanically ventilated patients. ${ }^{29}$

Elevated sound levels in ICUs mainly due to monitor alarms, equipment and the activities of health care personnel have been implicated in circadian disruption and sleep abnormalities in admitted patients. ${ }^{32}$ The type of respiratory support can also lead to asynchrony in biological rhythms. ${ }^{33}$ In this regard, we found smooth effect models which differed depending on the presence or absence of mechanical ventilation, but in both cases with peaks coinciding with the sound level peak.

In the ICU studied here, the elevated sound levels may have been caused by alarms that sounded when the patients' respiratory rate increased, particularly high minute volume or peak pressure alarms. Even when patients were not connected to mechanical ventilation at the time of aspiration, coughing produced by stimulation with the aspiration tube caused the monitor to detect a significant increase in the respiratory rate, as well as in the heart rate and blood pressure in the case of invasive arterial monitoring, thus triggering the alarm. Moreover, given that the sound level meter was located at the nursing station, it also recorded the alarms of the central monitor utilized for the eight beds in the ICU, although the sound levels of the ventilator alarms were more distant and less intense. Non-invasive mechanical ventilation can produce more noise and also a higher respiratory rate. However, since the sound level meter was not located at the patients' bedside, the recorded sound levels may have been lower.

A recent Cochrane systematic review ${ }^{34}$ assessed the action of melatonin in the promotion of adult sleep in ICUs. The most relevant finding was the reduction in the administration of psychoactive drugs/sedatives. However, the authors stated that the results were inconclusive due to the heterogeneity in the sedation protocol and the non-inclusion of other environmental variables. Therefore, future studies should control for these confounding variables and provide sufficient evidence to propose a possible intervention with melatonin in ICUs for the promotion of sleep.

\section{5 | IMPLICATIONS AND RECOMMENDATIONS FOR PRACTICE}

The findings of this study may be of interest to health professionals working in ICUs as they could help them to plan structured interventions that provide patients enough rest and avoid disruptions in their biological rhythms. The association over time of increases in physiological variables (heart and respiratory rate, Glasgow Coma Scale) and sound levels shows how the circumstances of the hospital environment impact the health of patients hospitalized in the ICU. The study results can also influence the decision of whether or not to design an open-albeit currently questioned-ICU system (e.g. extended visiting hours), as such designs affect sleep/wake cycles and circadian rhythms.

\subsection{Limitations}

Although many sound measurements have been made in a cardiovascular area of an ICU and several work shifts have been included, the results may not be generalizable to all cardiovascular wards. The fact that the measurements were made on non-continuous, random workdays and shifts may not fully reflect the clinical activity in the unit. However, daytime and nighttime periods have been considered, and through the soft effects model, this lack of continuity has been reduced.

Another limitation is that a single sound level meter located in the nursing post was used per work shift. Perhaps different values could have been obtained if additional sound level meters had been placed at different areas of the unit. Despite these limitations, we believe that the findings are of important clinical-care interest.

Factors such as the structure of the ICU or the amount of light that patients receive have not been considered. Therefore, staffing numbers and the season of the year should be taken into account in future studies. This study analysed clinical variables related to patient monitoring in the ICU. However, it would be necessary to include other variables, such as melatonin levels, to establish a cause-effect relationship.

\section{6 | CONCLUSION}

Our study found high sound levels in a cardiovascular ICU. Unlike other series using GAMM models, a link between sound, heart rate, respiratory rate and the Glasgow scale has been established. Specifically, we observed an association between increasing levels of sound, heart rate, respiratory rate and Glasgow Coma Scale at the same time.

The findings seem to indicate that the environmental conditions of the ICU influence certain variables related to patients' physiological state. In the studied ICU, no specific sound levels interventions were being carried out. Future intervention studies on these environmental conditions could be recommended, although variables such as the light, humidity and temperature of the unit need to be determined in prospective studies.

The results of this study could translate into structural changes in ICU facilities (construction, orientation and distribution of new units), as well as the development of clinical practice guidelines that influence the behaviour of health care professionals.

\section{CONFLICT OF INTEREST}

The authors declare that they have no potential conflict of interest. 


\section{AUTHOR CONTRIBUTIONS}

Ignacio Morales-Cané, Juan Antonio Moral-Arroyo, Ipek Guler, María Aurora Rodríguez-Borrego, Pablo Jesús López-Soto: Study design. Ignacio Morales-Cané, Juan Antonio Moral-Arroyo, Fabio Debbia, Francisca Llamas-Recio, Jose Manuel Jiménez-Pastor, Juan de la Cruz López-Carrasco: Data collection. Ignacio Morales-Cané, Ipek Guler, Darío ACuña-Castroviejo, Pablo Jesús López-Soto: Data analysis. Ignacio Morales-Cané, Juan Antonio Moral-Arroyo, María Aurora RodríguezBorrego, Pablo Jesús López-Soto: Study supervision. Ignacio Morales-Cané, Ipek Guler, María Aurora Rodríguez-Borrego, Pablo Jesús López-Soto: Manuscript writing. Ignacio Morales-Cané, Juan Antonio Moral-Arroyo, Fabio Debbia, Ipek Guler, Francisca Llamas-Recio, Jose Manuel JiménezPastor, Juan de la Cruz López-Carrasco, Darío ACuña-Castroviejo, María Aurora Rodríguez-Borrego, Pablo Jesús López-Soto: Critical revisions for important intellectual content.

\section{ETHICS STATEMENT}

The project was approved by the reference research ethics committee (Act no. 277, reference 3878) and carried out in accordance with the ethical principles established in the Declaration of Helsinki on Human Rights and Biomedicine, as well as the Spanish legislation on personal data protection.

\section{INFORMED CONSENT}

Patients were provided an information sheet and informed consent was obtained from all participants included in the study. If patients were unable to give their consent due to their clinical condition, consent was requested from families.

\section{ORCID}

Ignacio Morales-Cané (D) https://orcid.org/0000-0002-0604-6953 Juan de la Cruz López-Carrasco (D) https://orcid.org/0000-0003-37272731

Pablo Jesús López-Soto (D) https://orcid.org/0000-0002-1046-6686

\section{REFERENCES}

1. World Health Organization (WHO). Environmental Noise Guidelines for the European Region. Denmark: WHO; 2018 Retrieved October 14, 2019 from: http://www.euro.who.int/en/health-topics/environment-andhealth/noise/publications/2018/environmental-noise-guidelines-forthe-european-region-2018

2. Burrows AA. Acoustic noise, an informational definition. Human Fact $J$ Hum Fact Ergon Soc. 1960;2(3):163-168. doi:10.1177/001872086000 200308

3. Sliwinska-Kowalska M, Zaborowski K. WHO environmental noise guidelines for the European region: a systematic review on environmental noise and permanent hearing loss and tinnitus. Int $J$ Environ Res Public Health. 2017;14:1139. doi:10.3390/ijerph14101139

4. Kam PC, Kam AC, Thompson JF. Noise pollution in the anesthetic and intensive care environment. Anaesthesia. 1994;49:982-986.

5. Claes E, Vanwing S, Stessel B, Van Assche A, Jamaer L, Dubois J. Noise in the Intensive Care Unit: Fiction or Fact? . Belgium: Euroanaesthesia; Hasselt; 2016.

6. Berglund B, Lindvall T, Schwela DH. Guidelines for community noise. Geneva: WHO; 1999 Retrieved October 15, 2019 from: http:// whqlibdoc.who.int/hq/1999/a68672.pdf
7. Elliott R, Mc Kinley S, Cistulli P, Fien M. Characterization of sleep in intensive care using 24-h polysomnography: an observational study. Crit Care. 2013;17(2):R46.

8. Xie H, Kang J, Mills GH. Clinical review: the impact of noise on patients' sleep and the effectiveness of noise reduction strategies in intensive care units. Crit Care. 2009;13(2):208. doi:10.1186/cc7154

9. Litton E, Elliott R, Thompson K, Watts N, Seppelt I, Webb SAR. Using clinically accessible tools to measure sound levels and sleep disruption in the ICU: a prospective multi-center observational study. Crit Care Med. 2017;45:966-971.

10. Delaney LJ, Currie MJ, Huang HC, Lopez V, Litton E, Van Haren F. The nocturnal acoustical intensity of $\&$ the intensive care environment: an observational study. J Intensive Care. 2017;5:41.

11. Friese RS, Diaz-Arrastia R, McBride D, Frankel H, Gentilello LM. Quality and quantity of sleep in the surgical intensive care unit: are out patients sleeping? J Trau Acute Care Surg. 2007;63:1210-1214.

12. Billings ME, Watson NF. Circadian dysrhythmias in the intensive care unit. Crit Care Clin. 2015;31(3):393-402.

13. Fontana CJ, Pittiglio LI. Sleep deprivation among critical care patients. Crit Care Nurs Q. 2010;33(1):75-81. doi:10.1097/CNQ.0b013e3181c8e030

14. Devlin JW, Skrobik Y, Gélinas C, et al. Clinical practice guidelines for the prevention and Management of Pain, agitation/sedation, delirium, immobility, and sleep disruption in adult patients in the ICU. Crit Care Med. 2018;46(9):e825-e873. doi:10.1097/CCM.0000000000003299

15. Directive 2002/49/EC of the European Parliament and of the Council of June 25, 2002 relating to the assessment and management of environmental noise.

16. Royal Decree 286/2006, Spanish Official Bulletin number 22, of March 10, on the protection of the health and safety of workers against risks related to exposure to noise.

17. Knaus WA, Draper EA, Wagner DP, Zimmerman JE. APACHE II: a severity of disease classification system. Crit Care Med. 1985;13(10): 818-829.

18. Hsu SM, Ko WJ, Liao WC, et al. Associations of exposure to noise with physiological and psychological outcomes among post-cardiac surgery patients in ICUs. Clinics. 2010;65(10):985-989. doi: 10.1590/S1807-59322010001000011

19. Hastic T, Tibshirani R. Generalized additive models. Statis Sci. 1986;1: 297-310.

20. Nightingale F. Notes on Nursing: What it Is, and What it Is Not. New York, NY: Appleton; 1860.

21. Delaney LJ, Currie MJ, Carol Huang H, Lopez V, Van Haren F. "They can rest at home": an observational study of patients' quality of sleep in an Australian hospital. BMC Health Serv Res. 2018;18:524.

22. Elliot RM, McKinley SM, Eager D. A pilot study of sound levels in an Australian adult general intensive care unit. Noise Health. 2010;12:26-36.

23. Darbyshire JL, Young D. An investigation of sound levels on intensive care units with reference to the WHO guidelines. Crit Care. 2013;17:R187.

24. Tainter CR, Levine AR, Quraishi SA, et al. Noise levels in surgical ICUs are consistently above recommended standards. Crit Care Med. 2016; 44:147-152.

25. Delaney L, Litton E, Van Haren F. The effectiveness of noise interventions in the ICU. Curr Opin Anaesthesiol. 2019;32:144-119.

26. Pope DS, Gallun FJ, Kampel S. Effect of hospital noise on patients' ability to hear, understand, and recall speech. Res Nurs Health. 2013; 36:28-241.

27. Hagerman I, Rasmanis G, Blomkvist V, Ulrich R, Eriksen CA, Theorell T. Influence of intensive coronary care acoustics on the quality of care and physiological state of patients. Int J Cardiol. 2005;98:267-270.

28. Hsu T, Ryherd E, Persson Wayne K, Ackerman J. Noise pollution in hospitals: impact on patients. J Clin Outcom Manag. 2012;19:301-309.

29. Colton K, Dinardo T, Hu PF, et al. The ONPOING study group. Full of sound and fury, signifying noting: burden of transient noncritical monitor alarms in a trauma resuscitation unit. J Trau Nurs. 2013;20(4):184-188. 
30. McAndrew NS, Leske J, Guttormson J, Kelber ST, Moore K, Dabrowski S. Quiet time for mechanically ventilated patients in the medical intensive care unit. Intens Critic Care Nurs. 2016;35:22-27.

31. Alsulami G, Rice AM, Kidd L. Prospective repeated assessment of self-reported sleep quality and sleep disruptive factors in the intensive care unit: acceptability of daily assessment of sleep quality. BMJ Open. 2019;9(6):e029957.

32. Korompeli A, Muurlink O, Kavronchorianou $\mathrm{N}$, Katsoulas $\mathrm{T}$, Fildissis G, Baltopoulos G. Circadian disruption of ICU patients: a review of pathways, expression, and interventions. J Crit Care. 2017; 38:269-277.

33. Boyko Y, Holst R, Jennum P, Oerding H, Nikolic M, Toft P. Melatonin secretion pattern in critically ill patients: a pilot descriptive study. Crit Care Res Prac. 2017;7010854:1-8.
34. Pritchard MW, Schofield-Robinson OJ, Alderson P, Smith AF, Lewis SR. Melatonin for the promotion of sleep in adults in the intensive care unit. Cochrane Database System Rev. 2018;2018(5): CD012455.

How to cite this article: Morales-Cané I, Moral-Arroyo JA, Debbia $F$, et al. Impact of sound levels on physiological and consciousness state of cardiovascular patients. Nurs Crit Care.

2022;1-11. doi:10.1111/nicc.12746 